\title{
Erratum to: The Perioperative Anticoagulant Use for Surgery Evaluation (PAUSE) Study for Patients on a Direct Oral Anticoagulant who Need an Elective Surgery or Procedure: Design and Rationale
}

James D. Douketis ${ }^{1}$ Alex C. Spyropoulos ${ }^{2}$ Julia M. Anderson ${ }^{3}$ Donald M. Arnold ${ }^{1}$ Shannon M. Bates ${ }^{1}$ Mark Blostein ${ }^{4}$ Marc Carrier ${ }^{5}$ Joseph A. Caprini ${ }^{6}$ Nathan P. Clark ${ }^{7}$ Michiel Coppens ${ }^{8}$ Francesco Dentali $^{9}$ Joanne Duncan ${ }^{1}$ Peter L. Gross ${ }^{1}$ Jeannine Kassis ${ }^{10}$ Stephen Kowalski ${ }^{11}$ Agnes Y. Lee ${ }^{12}$ Gregoire Le Gal ${ }^{13}$ Geneviève Le Templier ${ }^{14} \quad \mathrm{Na} \mathrm{Li}^{1} \quad$ Elizabeth MacKay ${ }^{15}$ Vinay Shah ${ }^{16}$ Sudeep Shivakumar ${ }^{17}$ Susan Solymoss ${ }^{4}$ Frederick A. Spencer ${ }^{1}$ Summer Syed ${ }^{18}$ Alfonso J. Tafur ${ }^{6}$ Thomas Vanassche ${ }^{19}$ Thomas Thiele $^{20}$ Cynthia Wu ${ }^{21}$ Erik Yeo $^{22}$ Sam Schulman ${ }^{1}$

1 Department of Medicine, McMaster University, Hamilton, Canada

2 Department of Medicine, Hofstra Northwell School of Medicine, Northwell Health at Lenox Hill Hospital, New York, New York, United States

${ }^{3}$ Department of Medicine, University of Edinburgh, Edinburgh, United Kingdom

${ }^{4}$ Department of Medicine, McGill University, Montreal, Canada

${ }^{5}$ Ottawa Hospital Research Institute, University of Ottawa, Ottawa, Canada

6 NorthShore University Health Systems, Evanston, Illinois, United States

7 Department of Pharmacy, Kaiser Permanente Colorado, Aurora, Colorado, United States

8 Department of Vascular Medicine, Academic Medical Center, University of Amsterdam, Amsterdam, The Netherlands

${ }^{9}$ Department of Medicine and Surgery, Insubria University, Varese, Italy

${ }^{10}$ Department of Medicine, Université de Montréal, Montreal, Canada

11 Department of Anesthesiology, University of Manitoba, Winnipeg, Canada

12 Department of Medicine, University of British Columbia,

Vancouver, Canada

Thromb Haemost 2018;118:1679-1680.
Address for correspondence James D. Douketis, MD, St. Joseph's Healthcare Hamilton, Room F-544, 50 Charlton Avenue East, Hamilton, Ontario L8N 4A6, Canada (e-mail: jdouket@mcmaster.ca).

${ }^{13}$ L'Institut du Savoir Montfort, L'Hopital Monfort, Ottawa, Ontario, Canada

${ }^{14}$ Department of Internal Medicine, Centre Hospitalier Universitaire de Sherbrooke, Quebec, Canada

${ }^{15}$ Department of Medicine, University of Calgary, Calgary, Canada

${ }^{16}$ Department of Medicine, Henry Ford Hospital, Detroit, Michigan, United States

${ }^{17}$ Department of Medicine, Dalhousie University, Halifax, Canada

${ }^{18}$ Department of Anesthesiology, Hamilton Health Sciences, McMaster University, Hamilton, Canada

${ }^{19}$ Department of Cardiovascular Sciences, Universitaire Ziekenhuizen Leuven, Leuven, Belgium

${ }^{20}$ Institute for Immunology and Transfusion Medicine, Universitätsmedizin Greifswald, Greifswald, Germany

${ }^{21}$ Department of Medicine, University of Alberta, Edmonton, Canada

${ }^{22}$ Department of Medicine, University of Toronto, Toronto, Canada

\section{ERRATUM}

In the Original Article by Douketis et al. "The Perioperative Anticoagulant Use for Surgery Evaluation (PAUSE) Study for Patients on a Direct Oral Anticoagulant who Need an Elective Surgery or Procedure: Design and Rationale" (Thromb Haemost 2017;117:2415-2424; DOI: 10.1160/TH17-08-0553), the authors have identified two errors that they wish to correct:

First, on page 2419, second paragraph, Clinical Outcomes subheading, the authors state that, "The primary clinical outcomes are arterial thromboembolism, comprising stroke (ischemic or haemorrhagic), systemic embolism or transient ischemic attack and major bleeding." The inclusion of "haemorrhagic" stroke is incorrect as only ischemic strokes are included in their definition of an arterial thromboembolism outcome.

The definitions of study outcomes are correctly indicated in Appendix A (pg. 2424) of the paper, where the authors state: "The second primary outcome is arterial thromboembolism, comprising (1) ischemic stroke, defined as any new focal neurologic deficit that persists for $>24$ hours or any new focal neurologic deficit of any duration that occurs with evidence of acute infarction on computed tomography (CT) or magnetic resonance imaging (MRI) of the
DOI https://doi.org/ $10.1055 / \mathrm{s}-0038-1668582$. ISSN 0340-6245. 
brain; (2) systemic embolism, defined as symptomatic embolism to upper or lower extremity or abdominal organ, confirmed intraoperatively or by objective imaging studies (e.g. CT angiography) and (3) transient ischemic attack, defined as symptomatic focal neurologic deficit (lasting typically $<1$ hour) that occurs with no evidence of acute infarction on CT/MRI of the brain."

Second, the depiction of the pre-procedure interruption interval for dabigatran-treated patients with a $\mathrm{CrCl}<50 \mathrm{~mL} / \mathrm{min}$ is incorrect in Figure 1 (pg. 2418) of the paper, as the arrow should extend so it reflects 2 days off treatment (i.e., day -2 and day -1 ). The incorrect (currently published) version is shown below, with incorrect area shaded in red:

\begin{tabular}{|c|c|c|c|c|c|c|c|}
\hline \multirow[t]{2}{*}{ DOAC Type } & \multirow{2}{*}{$\begin{array}{c}\text { Surgery/procedure } \\
\text { Bleed risk }\end{array}$} & \multicolumn{5}{|c|}{ Pre-procedure Interruption Timing of DOAC } & \multirow[b]{2}{*}{ Day 0} \\
\hline & & Day -5 & Day -4 & Day -3 & Day -2 & Day -1 & \\
\hline \multirow{2}{*}{$\begin{array}{l}\text { Dabigatran } \\
(\mathrm{CrCl} \geq 50 \mathrm{~mL} / \mathrm{min})\end{array}$} & High & & & & & & \multirow{8}{*}{$\begin{array}{c}\text { no DOAC taken } \\
\text { on the day of } \\
\text { surgery/procedure }\end{array}$} \\
\hline & Low & & & & & & \\
\hline \multirow{2}{*}{$\begin{array}{l}\text { Dabigatran } \\
(\mathrm{CrCl}<50 \mathrm{~mL} / \mathrm{min})\end{array}$} & High & & & & & & \\
\hline & Low & & & & & & \\
\hline \multirow[t]{2}{*}{ Rivaroxaban } & High & & & & & & \\
\hline & Low & & & & & & \\
\hline \multirow[t]{2}{*}{ Apixaban } & High & & & & & & \\
\hline & Low & & & & & & \\
\hline
\end{tabular}

The corrected version should appear as follows, with extension of the arrow by one cell to the right the row pertaining to dabigatran, $\mathrm{CrCl}<50 \mathrm{~mL} / \mathrm{min}$ :

\begin{tabular}{|c|c|c|c|c|c|c|c|}
\hline \multirow[t]{2}{*}{ DOAC Type } & \multirow{2}{*}{$\begin{array}{c}\text { Surgery/procedure } \\
\text { Bleed risk }\end{array}$} & \multicolumn{5}{|c|}{ Pre-procedure Interruption Timing of DOAC } & \multirow[b]{2}{*}{ Day 0} \\
\hline & & Day -5 & Day -4 & Day -3 & Day -2 & Day -1 & \\
\hline \multirow{2}{*}{$\begin{array}{l}\text { Dabigatran } \\
(\mathrm{CrCl} \geq 50 \mathrm{~mL} / \mathrm{min})\end{array}$} & High & & & & & & \multirow{8}{*}{$\begin{array}{c}\text { no DOAC taken } \\
\text { on the day of } \\
\text { surgery/procedure }\end{array}$} \\
\hline & Low & & & & & & \\
\hline \multirow{2}{*}{$\begin{array}{l}\text { Dabigatran } \\
(\mathrm{CrCl}<50 \mathrm{~mL} / \mathrm{min})\end{array}$} & High & & & & & & \\
\hline & Low & & & & & & \\
\hline \multirow[t]{2}{*}{ Rivaroxaban } & High & & & & & & \\
\hline & Low & & & & & & \\
\hline \multirow[t]{2}{*}{ Apixaban } & High & & & & & & \\
\hline & Low & & & & & & \\
\hline
\end{tabular}

The authors apologize for these errors and would be happy to address any questions or clarifications regarding these corrections. 